\title{
Synthesis of Ag Nanoparticles Decorated Carbon Nanotubes as an Electrochemical Sensor for Determination of Phenolic Compounds in Shale Gas Wastewater
}

\author{
Yugao Zhu ${ }^{1, *}$, Lintao Yang ${ }^{2}$ \\ ${ }^{1}$ Yan'an vocational and Technical College, Chemical engineering institute, Yanan, 716000, China \\ ${ }^{2}$ Shenyang Research Institute of Chemical Industry Co. Ltd. \\ *E-mail:shanxi1850299@ sina.com
}

doi: $10.20964 / 2021.07 .10$

Received: 4 March 2021/ Accepted: 13 April 2021 / Published: 31 May 2021

In this study, silver nanoparticles (Ag NPs) were decorated on carbon nanotubes (CNTs) for electrochemical determination of o-cresol and phenol as phenolic compounds in shale gas wastewater. The glassy carbon electrode (GCE) surface was modified with functionalized CNTs (CNTs/GCE) and Ag NPs were electrodeposited on CNTs/GCE (Ag NPs/CNTs/GCE). Morphology and structures analysis of synthesized electrodes were done using SEM and XRD which exhibited that the uniformly Ag NPs in fcc structure were electrodeposited on the side wall of CNTs. Electrochemical studies with cyclic voltammetry (CV), differential pulse voltammetry (DPV) and amperometry illustrated that there are stable and sensitive electrochemical signal for Ag NPs/CNTs/GCE due to enhancement of the surface area by synergetic effects of CNTs and Ag NPs. Electrochemical studies represented that the limit of detection, sensitivity and linear range of sensor were obtained $0.01 \mu \mathrm{M}, 0.20046 \mu \mathrm{A} / \mu \mathrm{M}$ and 10 to 200 $\mu \mathrm{M}$, respectively, for detection of o-cresol and $0.01 \mu \mathrm{M}, 0.29759 \mu \mathrm{A} / \mu \mathrm{M}$ and 10 to $160 \mu \mathrm{M}$, respectively for determination of phenol. The selectivity and applicability of the sensor was considered to determine phenolic compounds in the prepared real sample of shale gas wastewater which implied the o-cresol concentration and phenol in the real sample were achieved $0.97 \mu \mathrm{M}$ and $0.69 \mu \mathrm{M}$, respectively.

Keywords: Ag nanoparticles; Carbon nanotubes; Electrochemical sensor; Phenolic compounds; Shale gas wastewater

\section{$\underline{\text { FULL TEXT }}$}

(C) 2021 The Authors. Published by ESG (www.electrochemsci.org). This article is an open access article distributed under the terms and conditions of the Creative Commons Attribution license (http://creativecommons.org/licenses/by/4.0/). 